\title{
Para variar, otra variante: ómicron.
}

\author{
For varying, another variant: omicron.
}

Agustín Zerón*

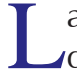
as olas en esta pandemia de COVID-19 siguen teniendo repuntes con elevados casos de infección. El árbol genealógico de la nueva variante lo ha clasificado como B.1.1.529-NU, identificando algunos cambios en su codificación genética. Esta variante parece que se desarrolló en Botsuana, sur de África, pero hay publicaciones que refieren su extensión en Europa antes que en Hong Kong y otros países. Esta nueva variante del SARS-CoV-2 tiene al menos 32 mutaciones en su secuencia genómica de la proteína $\mathrm{S}$ (spike o espiga), y es mucho más transmisible que la variante delta, por lo que en unos días podría convertirse en una variante dominante.

Ómicron se reportó el 24 de noviembre, pero es probable que la variante se haya desarrollado semanas antes en otro lugar. Con datos epidemiológicos realizados en Alemania, se demostró que ómicron ya estaba aislado 10 días antes que en el sur de África. El 26 de noviembre la Organización Mundial de la Salud (OMS) clasificó a ómicron (B.1.1.529-NU) como variante de preocupación. El 7 de diciembre ya estaba reportado en más de 50 países, incluyendo México.

La OMS decidió en mayo de 2021 denominar a las variantes de la COVID-19 con el nombre de las letras del alfabeto griego para no estigmatizar y discriminar a ninguna población, como podía suceder anteriormente, ya que se estaba bautizando a las mutaciones del virus en función del primer lugar donde era detectada. Sin embargo, aunque ahora sería el turno de la letra ' $N i^{\prime}$, que se pronuncia $\mathrm{Nu}$, la OMS ha decidido rechazar dicho nombre para no confundirse fácilmente con la palabra 'new' (nuevo) en los países anglosajones. Por otro lado, se ha desechado a
\end{abstract}

su vez la letra ' $X i$ ' por ser un apellido común en algunos países de Asia y así evitar causar cualquier ofensa a nivel cultural, social, nacional, regional, profesional o de etnias.

La clasificación como variante de preocupación es debido principalmente a su alta transmisibilidad. Las variantes a la fecha desde alfa $(\alpha)$, beta $(\beta)$, gamma $(\gamma)$, delta $(\delta)$, lambda $(\lambda)$ tienen sublinajes. Ahora la variante

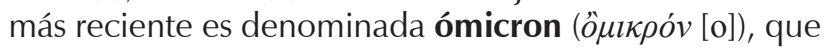
es la decimoquinta letra del alfabeto griego (Figura 1).

\section{¿DEBEMOS PREOCUPARNOS?}

Recientemente habíamos compartido que la OMS desarrolló un sistema para clasificar a las variantes más importantes del virus SARS-CoV-2: independientemente de enumerarlas con el alfabeto griego: $\boldsymbol{\alpha}, \boldsymbol{\beta}, \boldsymbol{\gamma}, \boldsymbol{\delta}$, incluso algunos reportes ya detectaban variantes lambda o $\boldsymbol{\lambda}$. La aparición de tantas variantes supondría un mayor riesgo para la salud pública mundial, y se decidió nombrar a las variantes en dos categorías más específicas: variante de interés (VOI [variant of interest]) y variante preocupante (VOC [variant of concern]), con el fin de priorizar el seguimiento e investigación a escala mundial. La variante ómicron es una variante preocupante. La situación epidemiológica en varios países se ha caracterizado por tres picos distintos en los casos notificados, el último de los cuales había sido predominantemente la variante delta. En las últimas semanas, las infecciones fueron aumentado considerablemente, coincidiendo con la detección de la variante B.1.1.529. La variante B.1.1.529 presenta un gran número de mutaciones, algunas de las cuales son

\footnotetext{
* Endoperiodontólogo recertificado. Editor en Jefe de la Revista ADM. México. 
preocupantes. Las pruebas iniciales indican que el riesgo de reinfectarse por esta variante es mayor que con otras variantes preocupantes $y$, al parecer, el número de casos que ocasiona está aumentando rápidamente en todo el mundo (Figura 2).

Mundialmente se reportan 5'341,760 muertes por COVID-19, y en México se estima que han fallecido aproximadamente 650,000 personas, la curva no se aplana y apretadamente se ha vacunado al 52\% de la población, sin vacunar todavía a los menores de edad, y menos con los refuerzos de una tercera dosis con AstraZeneca, tercera dosis que es indispensable para los trabajadores de la salud y a quienes sólo recibieron dosis de vacuna CanSino y Sinovac.

Pero no todo debe ser preocupación. Una de las 32 mutaciones encontradas en ómicron es la que ha desarrollado más esperanzas, ya que las teorías evolutivas del coronavirus encuentran secuencias iguales a las del virus HCoV-229E del resfriado común. El HCoV-229E o cepa $229 \mathrm{E}$ fue aislada en 1966, en conjunto con otros virus de muestras del tracto respiratorio humano de pacientes resfriados. El HCoV-229E es uno de los siete

Figura 1:

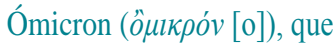
es la decimoquinta letra del alfabeto griego.

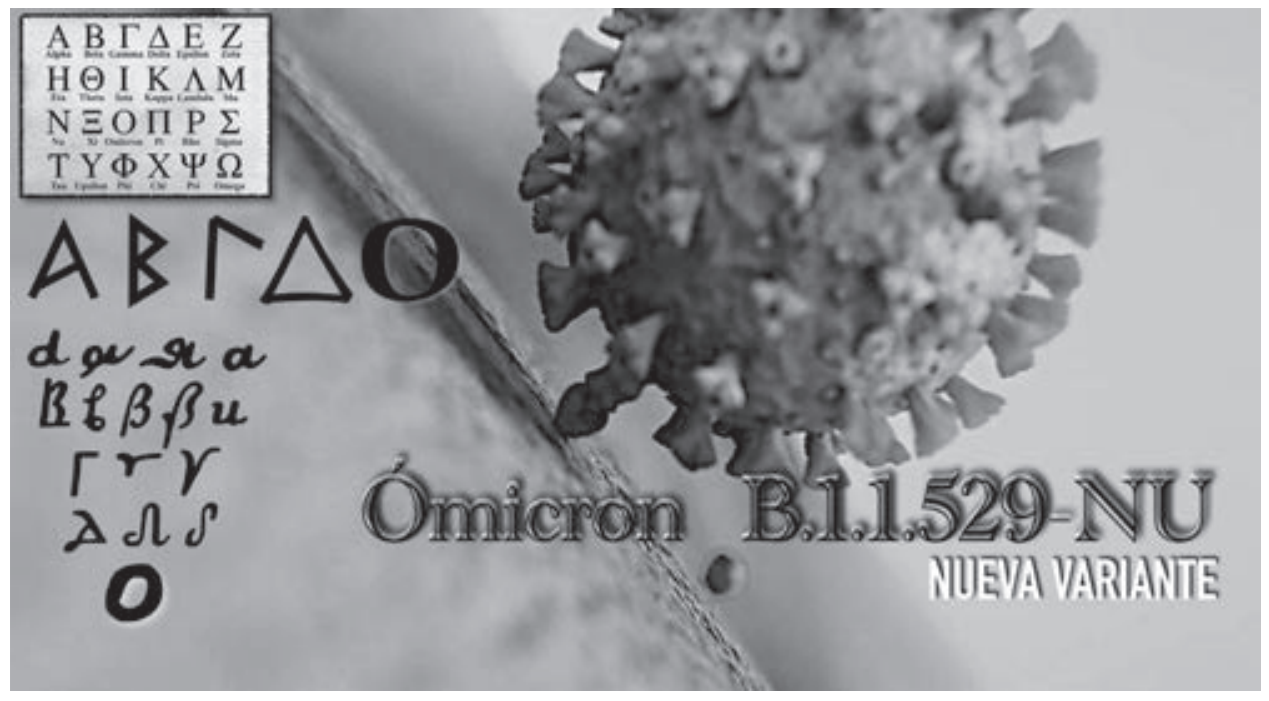

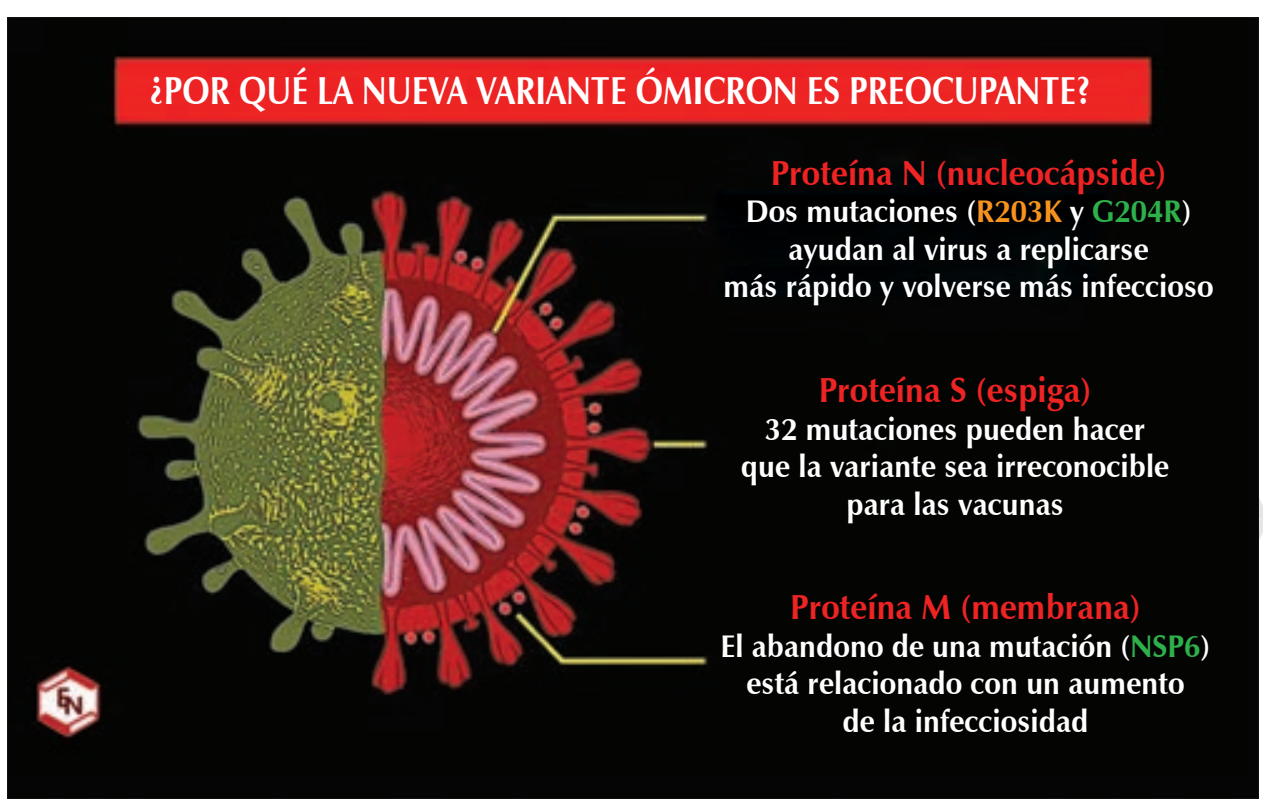

Figura 2:

La variante ómicron con 32 mutaciones en la proteína $\mathrm{S}$ (espiga) representa la principal variante preocupante. 
coronavirus conocidos que infectan más frecuentemente a los seres humanos, los datos clínicos de la infección estacional incluyen malestar general, cefalea, secreción nasal, estornudos y dolor de garganta. Una pequeña porción de los pacientes (10-20\%) presentará fiebre y tos. Por lo anterior, es clínicamente indistinguible de las infecciones de vías respiratorias causadas por otros patógenos, como el rinovirus y la influenza $\mathrm{A}$. Al igual que estos virus, su localización y distribución es a nivel mundial.

Los virus cambian (mutan) constantemente, y una vez que saltan la barrera de especie son eficientes en la propagación de humano a humano, se establecen en el ecosistema, circulan en el medioambiente durante meses o años hasta que nuestro organismo, al ir reconociendo las mutaciones, conformará una respuesta inmunitaria adaptativa. Para que esto suceda pasarán algunos años para que el coronavirus se reconozca como estacional, y entonces las vacunas lleguen a cumplir su papel preventi- vo. Y en lo verdaderamente preventivo, hemos aprendido mucho, no se puede depender sólo de las vacunas, ni del número de dosis. Los virus entran cuando el cubrebocas o las defensas se bajan.

A dos años del hallazgo de Wuhan, ahora en el final del 2021 ha surgido otra variante que a muchos ya no ha sido preocupante, pero en estas fiestas decembrinas, vale envolver un mensaje de esperanza y paz. Y ante la entrada de un año nuevo, el optimismo científico surge al iniciar los análisis genómicos en los antecedentes evolutivos de los coronavirus, para sobreponer las próximas mutaciones, con la vacunación y las próximas «píldoras» anti-COVID, donde el SARS-CoV-2 será menos mortal y se convierta en otro virus endémico, tal como la gripe y la influenza. iFeliz, próspero y metaverso 2022!

\author{
Correspondencia: \\ Dr. Agustín Zerón \\ E-mail: periodontología@hotmail.com
}

